\title{
Vivências de Discriminação e Resistência de uma Prostituta Negra
}

\author{
Raquel de Freitas Banuth \\ Universidade de São Paulo, São Paulo, SP, Brasil.
}

\author{
Manoel Antônio dos Santos \\ Universidade de São Paulo, São Paulo, SP, Brasil.
}

Resumo: Este estudo teve por objetivo compreender as vivências de exclusão, discriminação e resistência de uma profissional do sexo negra, que trabalhava em uma casa de prostituição do interior de São Paulo. Utilizou-se entrevista semiestruturada e observação participante com uma mulher negra, que trabalhava em uma casa onde todas as outras profissionais eram brancas. A análise de dados foi orientada pelo modelo proposto por Braun e Clarke e abordou as principais categorias temáticas que concernem ao desenvolvimento profissional no universo das profissionais do sexo. Os relatos mostraram que as colegas de trabalho e os clientes empreendiam um processo de marcada exclusão da entrevistada, baseado no fato de ela pertencer a um grupo racial diferente dos demais. Apesar de enfrentar a "exclusão dentro da exclusão", a participante não legitimou o preconceito do qual era vítima e, para combatê-lo, lançou mão de estratégias para minimizar o impacto que a discriminação racial exercia sobre ela.

Palavras-chave: Prostituição, Profissionais do Sexo, Racismo, Gênero, Preconceito.

\section{Experiences of Discrimination and Resistance of a Black Prostitute}

\begin{abstract}
This study aimed to understand the experiences of exclusion, discrimination and resistance in the speech of a black sex worker, who works in a brothel in the country side of São Paulo state, Brazil. The participant observation methodology was used and a semi-structured interview was conducted with a black woman who worked in a house where all other professionals were white. Data analysis was guided by the Braun and Clarke model and addressed the main themes that concern the professional development in the world of sex workers. Reports showed that the co-workers and customers undertook a remarkable process of exclusion of the interviewee, based on the fact that she belonged to a different racial group. Despite facing the "exclusion within the exclusion", the participant did not legitimize the prejudice which she was victim of and, therefore, made use of strategies to minimize the impact that racial discrimination had on her.
\end{abstract}

Keywords: Prostitution, Sex Workers, Racism, Gender, Prejudice. 


\title{
Experiencias de Discriminación y Resistencia de una Prostituta Negra
}

\begin{abstract}
Resumen: Este estudio tuvo como objetivo comprender las experiencias de exclusión, discriminación y resistencia de una trabajadora sexual negra, que trabaja en un burdel en una ciudad en el interior del estado de São Paulo, Brasil. Fueron utilizadas observación participante y entrevistas semiestructuradas con una mujer negra que trabajaba en una casa donde todas las otras profesionales eran blancas. El análisis de los datos se basó en el modelo propuesto por Braun and Clarke y abordó los principales temas que conciernen al desarrollo profesional en el mundo de las trabajadoras sexuales. Los informes muestran que las compañeras de trabajo y los clientes llevaron a cabo un notable proceso de exclusión de la persona entrevistada, basado en el hecho de que ella pertenecía a un grupo racial diferente al de las demás. A pesar de enfrentar la "exclusión dentro de la exclusión", la participante no aprobó el prejuicio del que era víctima, y para lograr éxito, utilizó estrategias para minimizar el impacto que la discriminación racial ejercía sobre ella.
\end{abstract}

Palabras clave: Prostitución, Trabajadores Sexuais, Racismo, Género, Prejuicio.

\section{Introdução}

A discursivização do trabalho sexual dá margem para diferentes conceitos sobre a pessoa que trabalha como profissional do sexo. Na perspectiva do jurista, é a pessoa que usa do "comércio habitual do próprio corpo para satisfação sexual de indiscriminado número de pessoas" (Delmanto, 1991). Segundo a classificação do Ministério do Trabalho e do Emprego, são mulheres que "buscam programas sexuais, atendem e acompanham clientes, participam em ações educativas no campo da sexualidade" (Brasil, 2008). Para Cátia, prostituta entrevistada por Leticia Barreto, trabalhar nesse campo se define de forma bem mais singela: é saber "dar prazer" (Barreto, 2013, p. 117).

Como atividade humana milenar, a prostituição integra uma larga variedade de práticas, sentimentos e ações. Por isso, é difícil tentar definir essa atividade e circunscrevê-la a conceitos restritos. Definir a prostituição como uma forma de escravidão e submissão é ignorar o prazer, o desejo e a autonomia que permeiam o exercício dessa atividade profissional. Em contrapartida, afirmar que a prostituição é uma profissão que só traz prazer é negligenciar as formas de exploração, exposição a riscos e preconceitos aos quais a prostituta está exposta em seu cotidiano (Barreto, 2013). Portanto, deve-se olhar para a prostituição com um olhar cuidadoso e despido de juízos morais, buscando escapar de posições dogmáticas e sentenças de senso comum, como condenar implici- tamente a atividade ao generalizar que todas as prostitutas são vítimas da sociedade patriarcal. Inversamente, estaríamos idealizando a profissão ao afirmar que prostituir-se é uma escolha livre e autônoma de todas as pessoas que se prostituem. Também não é uma posição prudente ignorar as inúmeras peculiaridades que a profissão oferece e os riscos aos quais suas praticantes estão expostas, especialmente em países em que essa atividade laboral não é legalizada, como é o caso de nosso país.

No Brasil, a prostituição não é uma atividade criminalizada. No entanto, praticamente todas as suas atividades correlatas são crimes tipificados pelo Código Penal (Brasil, 1940): favorecimento da prostituição, manter casa de prostituição e rufianismo, que consiste em participar diretamente dos lucros da prostituição de outrem (Brasil, 1940). Portanto, apesar de não criminalizada, e até mesmo fazer parte do rol de profissões da Classificação Brasileira de Ocupações (Brasil, 2008), a prostituição ainda é uma atividade muito dificultada em razão da criminalização de outras atividades que a viabilizam.

Segundo Rubin (1984/1993), as práticas e discursos sociais discriminatórios têm um efeito mais importante sobre os indivíduos do que o que prega a lei. Desse modo, o fato de a prostituição não ser criminalizada no Brasil não impede que uma das dificuldades enfrentada por quem se prostitui seja o peso do estigma que lhe é imposto pelos discursos sociais hegemônicos. 
Neste estudo elegemos como objeto de investigação a mulher que se move nas trilhas da prostituição feminina, por entendermos que ela envolve códigos, estratégias de sobrevivência e práticas sociais que involucram significados diferentes do universo da prostituição masculina (Moscheta, McNamee, \& Santos, 2013; Santos, 2010, 2011).

A prostituição está eivada de preconceitos, resultantes da estigmatização da mulher que trabalha no mercado do sexo. Por estar à margem dos discursos sociais hegemônicos, materializados em instâncias diversas como o Estado, a ideologia das camadas sociais médias e as masculinidades prestigiosas (Olivar, 2011), a prostituição também pode ser encarada pelo viés da marginalização e da estigmatização. Desde o século XIX, a prostituição vem sendo associada a tráfico, escravidão e patologia, o que reveste a atividade de um significado moralista e de caráter fortemente depreciativo e pejorativo (Mayorga, 2011).

Em embates teóricos e disputas internas travadas dentro do feminismo, a prostituição tem sido significada de diferentes maneiras. De acordo com Piscitelli (2005), que aborda a prostituição sob a perspectiva do gênero, a maneira que se significa a prostituição está atrelada ao modo como se percebe a sexualidade. Há grupos feministas que entendem a sexualidade como um elemento utilizado para objetificar as mulheres, portanto, a prostituta seria inerentemente vítima de violência, objeto sexual e carente de poder. Por outro lado, determinados grupos, que enxergam a sexualidade como potencial arena libertadora para as mulheres, compreendem a prostituta como o símbolo da autonomia sexual das mulheres (Piscitelli, 2005).

A sexualidade é um dos principais focos dos dispositivos de controle social, que têm reservado às mulheres papéis específicos, relacionadas com sua natureza, capacidade de reprodução, atenção à família, incapacidade de atuação no espaço público e frágil participação política. Desse modo, a prostituta é frequentemente significada como desviante, devassa, mulher sem caráter e com propensão a ser escrava, e ainda como aquela que nega a natureza feminina (Mayorga, 2011).

Dito isso, percebe-se que o mercado do sexo é atravessado pelas marcas de gênero (Piscitelli, 2005). Por esse motivo, e também para ampliar a compreensão do presente estudo, é importante que se reflita sobre a temática do gênero. A partir de 1970, o feminismo se apropriou do gênero como categoria analí- tica para a compreensão da sociedade. Nessa acepção, gênero pode ser definido como uma construção sócio-histórica de relações de desigualdade estabelecidas entre homens e mulheres (Mayorga, Coura, Miralle, \& Cunha, 2013).

Recentemente, críticas têm sido endereçadas aos limites da noção de gênero, e a tendência do debate feminista atual é conceber que "mulher" não é uma categoria unitária. Segundo Brah (2006), mulheres não existem simplesmente como mulheres, mas como categorias diferenciadas, e cada categoria se refere a uma condição social específica. A categoria gênero mostra-se limitada para delimitar os eixos que tangenciam a construção do próprio sistema de gênero, tais como classe, raça e política heterossexual (Mayorga et al., 2013).

Nesse sentido, no fim dos anos 1990, emergiram no debate internacional feminista categorias que, articuladas à de gênero, permeiam o social e remetem à existência de diferenciações entre as mulheres. São as categorias de articulação e/ou interseccionalidades (Piscitelli, 2008). Interseccionalidade é o estudo das intersecções entre formas ou sistemas de opressão, dominação ou discriminação. A experiência de vida de uma mulher negra não pode ser entendida perfeitamente em termos de ser mulher ou de ser negra, consideradas de forma independente. Deve-se incluir a interação entre essas duas condições, que se influenciam reciprocamente. Essa concepção teórica foi apresentada pela primeira vez por Crenshaw (2002), abrindo um campo inovador nos estudos de gênero.

A emergência de estudos sobre as categorias de articulação é auspiciosa porque reconhece a articulação de diversos fatores na produção de vivências sociais (Mayorga et al., 2013), permitindo compreender com maior profundidade as diferentes vivências observadas entre as mulheres. Longe de ser um grupo homogêneo - como argumentava o feminismo de segunda onda - se diferenciam entre si: há negras lésbicas, mães trabalhadoras, mulheres transexuais de camadas médias, para mencionar apenas algumas possibilidades.

Uma categoria de articulação que consiste em forte marcador de diferença social é a "raça". Tal como Ferreira e Camargo (2011), consideramos que o conceito de "raça", do ponto de vista da genética, é pouco operacional e sem valor científico. Atualmente, admite-se que raça é uma construção social que classifica e tipifica os indivíduos em função de 
suas características fenotípicas perceptíveis. A partir de práticas e discursos sociais, a categoria "raça" contribui para fomentar processos de exclusão, discriminação e preconceito.

Segundo VandeBos (2010), o preconceito pode ser definido como atitude negativa em relação à outra pessoa ou grupo, formada em antecipação de alguma experiência com aquela pessoa ou grupo. Inclui três componentes: afetivo, cognitivo e comportamental. Tende a ser resistente à mudança na medida em que prevalece uma percepção distorcida do indivíduo em relação ao grupo ao qual pertence. Segundo o autor, há tipos específicos de preconceito, dependendo da informação sobre a qual se sustenta o julgamento. Quando baseado em aspectos raciais, é considerado racismo. Na legislação brasileira, as atitudes discriminatórias que esse preconceito engendra podem ser tipificadas como crime hediondo.

Preconceito racial é "um julgamento de valor, construído culturalmente e destituído de base objetiva, que faz parte da classe de crenças desenvolvidas através da socialização" (Ferreira, \& Camargo, 2011, p. 376). Já a discriminação racial é a manifestação comportamental do preconceito. O preconceito, expresso em práticas de discriminação racial, mantém os privilégios do grupo dominante às custas do prejuízo dos direitos dos indivíduos discriminados.

Ao abordar a prostituição em um contexto de imigração e sob a perspectiva das categorias de diferenciação, Mayorga (2011) afirma que, entre mulheres brancas e negras imigrantes, existe uma relação de poder e as mulheres negras têm sido historicamente designadas como "outras", ou seja, a elas são atribuídas características relacionadas com o que é exótico, raro, vítimas ou sujeitos menos conscientes de sua situação. A autora argumenta que a sexualização da raça negra é também bastante recorrente, em um processo que atinge não apenas a sexualidade das mulheres afrodescendentes, mas também de homens negros.

Crenshaw (2002), advogada e proeminente estudiosa do debate das interseccionalidades, adota uma abordagem sistêmica na discussão sobre as categorias de articulação. As interseccionalidades, segundo a autora, são uma forma de apreender as consequências da interação entre diferentes sistemas de subordinação, como o sexismo e o racismo. Note-se que a autora fala em interação, para evidenciar a ideia de que os sistemas de subordinação atuam em conjunto sobre o sujeito, superando a ideia de sobreposições de opressões. Na visão de Crenshaw, ações específicas geram opressões que fluem e confluem ao longo dos sistemas de subordinação e, no adensamento das suas confluências, geram o desempoderamento do indivíduo.

Outra autora relevante nesse debate, McKlintock (1995), que adota uma abordagem construcionista social, afirma que as categorias de articulação existem dentro de e por meio de relações. A autora afirma que poder e resistência, dinheiro e sexualidade, raça e gênero travam relações íntimas, contraditórias e recíprocas. Para ela, o feminismo trata tanto de sexualidade quanto de classe, raça, força de trabalho e economia, portanto, essas categorias não podem ser ignoradas na compreensão do papel social da mulher. Ainda segundo McKlintock, no cruzamento das relações de opressão é possível encontrar estratégias para a mudança. Essa concepção atribui ao sujeito agência e possibilidade de resistência contra a opressão sentida, por meio da coerção, negociação, cumplicidade, recusa, dissimulação, mimetismo, compromisso, afiliação e revolta.

Para conceituar a interação entre racismo e sexismo, Kerner (2012) aponta para a existência de três dimensões de racismo: epistêmica, institucional e pessoal. Na dimensão epistêmica, a interseccionalidade implica que estereótipos e atributos da feminilidade negra são diferentes das normas de gênero atribuídas às mulheres brancas. Na dimensão institucional, a intersecção entre racismo e sexismo se expressa pelo entrelaçamento entre diferentes estruturas institucionais, que resulta na diferenciação entre o papel tradicional da mulher branca e o da mulher negra, sendo que o papel social da primeira nunca se constitui de fato como uma realidade para a segunda. Na dimensão pessoal, racismo e sexismo se relacionam na construção de processos de formação da identidade branca e negra com distintos pontos de referência. Assim, a identidade de indivíduos pertencentes a minorias étnicas é marcada mais fortemente por registros étnicos do que a identidade de indivíduos pertencentes a grupos étnicos majoritários.

O presente estudo teve por objetivo compreender como o pertencimento à categoria racial "negra" permeia as vivências de uma prostituta em seu ambiente de trabalho, criando situações de marginalização e discriminação. Além disso, o estudo visa investigar como estar situada em uma posição de marginalidade permite a construção de uma postura 
de enfrentamento e resistência, e que estratégias são adotadas pela mulher em questão para se insurgir contra a discriminação racial.

\section{Percurso metodológico}

Trata-se de um estudo de caso instrumental, que tem por objetivo fornecer subsídios para a compreensão de um fenômeno mais amplo (Stake, 2000). Nesse tipo de enfoque, espera-se que o leitor associe suas experiências prévias às interpretações feitas pelos autores do estudo (Peres, \& Santos, 2005). O método utilizado para a coleta de dados foi a observação participante e o referencial teórico adotado foram os estudos de gênero.

A participante recebeu o nome fictício de Sofia. Para arregimentá-la para essa investigação, durante dois meses realizei visitas semanais a uma casa de prostituição feminina, situada em um município do interior paulista. A imersão no campo foi permeada por observação participante e a realização de entrevistas com as trabalhadoras sexuais, com a mulher que administrava o negócio e com alguns clientes.

Como instrumentos para coleta dos dados foram utilizados: roteiro de entrevista semiestruturada e diário de campo. O roteiro abordava questões relativas à trajetória de vida da participante, incluindo suas relações familiares e sociais, ingresso no universo do trabalho sexual, cuidados com a saúde e prevenção de doenças sexualmente transmissíveis. A entrevista teve duração de 55 minutos e foi realizada no local de trabalho, em uma sala reservada.

A entrevista foi audiogravada e, posteriormente, transcrita na íntegra e literalmente. A história de Sofia, por ser ela a única prostituta tida como negra que trabalhava no local, apresenta algumas peculiaridades que destoam das profissionais do sexo brancas que atuavam na casa, que foram reveladas gradualmente durante o trabalho de campo e no processo de aproximação gradual à participante. Graças às sutilezas da escuta, a análise terminou por desvendar dimensões que permitiram articular os sentidos do material produzido. Por isso, após uma inspeção preliminar do corpus de pesquisa, considerou-se que esse material merecia uma análise aprofundada para ser compreendido, o que em nosso entendimento justifica a proposição de um estudo de caso individual.

Os relatos foram organizados pelo método de Análise de Conteúdo na modalidade temática (Braun,
\& Clarke, 2006), e analisados segundo o referencial teórico dos estudos de gênero. A participante formalizou sua concordância em participar da pesquisa por meio da assinatura do Termo de Consentimento Livre e Esclarecido. O projeto de pesquisa foi aprovado pelo Comitê de Ética em Pesquisa da instituição universitária à qual os pesquisadores estão vinculados.

\section{Resultados e discussão}

O local de trabalho de Sofia é uma casa no centro da cidade. A participante da pesquisa pratica o que se denomina médio meretrício (Gaspar, 1985), que é a prostituição praticada em boates e casas de massagem. Essa modalidade de comércio sexual é caracterizada pelo cuidado das garotas com a aparência física e pelo fato de o preço cobrado pelo programa ser o mesmo para todas as garotas que trabalham no local. Assim, a variação no preço ocorre de acordo com a localização da casa. Silvia, a dona da casa, administra o negócio em parceria com o ex-marido. O horário de funcionamento é das 10 h00 às $22 \mathrm{~h} 00$, todos os dias, ininterruptamente.

As 15 mulheres que trabalhavam no contexto investigado se dividiam em dois turnos de trabalho. O valor do programa é fixado em 100 reais e, de cada programa feito, 35 reais devem ser pagos à casa. Por programa entende-se o tempo total que a profissional passa com o cliente. $\mathrm{O}$ valor de 35 reais é pago por programa feito, e não por dia de trabalho. No arranjo comercial estabelecido com a dona da casa, se uma mulher não faz qualquer programa em um dia, ela não deve nada à casa.

Sofia tem 27 anos, embora aparente ter mais idade. Apesar de ter estudado até a quarta série, afirma que não sabe ler nem escrever. Percebi seu analfabetismo porque ela teve dificuldades em assinar o Termo de Consentimento Livre e Esclarecido. Com certo constrangimento, ela se justificou dizendo ser analfabeta. Sofia afirma se envergonhar disso e, por essa razão, prefere ocultar o fato das outras mulheres que trabalham na casa. Já bastante estigmatizada e marginalizada na casa por ser negra, a hipótese levantada é que Sofia não quer ser vinculada a outra categoria de diferenciação, a de analfabeta. Ocultar que não sabe ler nem escrever pode ser uma forma de se proteger ou, pelo menos, de tentar amenizar a discriminação da qual é vítima na casa, como se verá a seguir.

Sofia trabalha como profissional do sexo há quatro anos. Refere ser essa a única profissão que já 
exerceu na vida. $\mathrm{O}$ motivo alegado para ter iniciado esse trabalho foi o nascimento prematuro do filho, agora com sete anos, e os problemas de saúde que ele teve quando bebê, que acarretaram dificuldades financeiras à família. Sofia conta que foi abandonada pelo pai da criança quando ele soube da gravidez. Diz que queria "dar" a criança para uma tia, mas foi impedida pela mãe. Hoje ela se sente aliviada por não ter entregado o filho, pois acredita que teria se arrependido. $\mathrm{O}$ menino morou com a avó, falecida à época da entrevista, até os dois anos de idade; Sofia forneceu os cuidados necessários, arcando com alguns encargos financeiros, além de cuidar dele enquanto a mãe ia trabalhar.

\section{A trajetória de Sofia na prostituição}

Sofia relata que "iniciou na vida" em uma cidade próxima, de menor porte se comparada com a que trabalha atualmente. Com a mudança de cidade, seus ganhos financeiros aumentaram. Ela conta que, na cidade menor, "só perdeu tempo" e que "agora sim" ela "sabe o que é dinheiro". Sofia sempre fez "programas na rua", isto é, buscava seus clientes em uma avenida conhecida na cidade por ser ponto de prostituição. Essa prática é denominada baixo meretrício (Gaspar, 1985).

Dois anos atrás ela havia se envolvido amorosamente com um cliente. Em pouco tempo foi morar com ele e parou de se prostituir. Dois anos depois, o marido - assim ela se refere a seu parceiro - foi preso, acusado de associação ao tráfico de drogas. Sem o auxílio financeiro do companheiro, Sofia não conseguia sustentar a si e o filho e, por isso, voltou a se prostituir, mas não mais a céu aberto. Pela primeira vez teve que encarar outro tipo de prostituição. Começou a trabalhar na casa porque o parceiro sente ciúmes e não admite que ela ganhe a vida como prostituta, mesmo enquanto ele está encarcerado e não pode prover-lhe o sustento. Por ter medo de ser vista na rua por algum conhecido do marido, que poderia delatá-la a ele, escolheu trabalhar em um local onde estaria mais protegida de ser vista.

Sofia: Mas agora nós largamos, largamos, ele foi preso, né. Aí foi onde que eu peguei e vim pra cá, porque eu não posso trabalhar na avenida, entendeu?

Pesquisadora: Por causa dele? Mas por quê?
Sofia: Ele é traficante, ele fica mandando o povo ficar me vigiando. Aí o povo fica passando lá na avenida para ver se eu estou lá. Estou trabalhando aqui escondido, não posso trabalhar em outro lugar.

Nota-se que o ex-marido, mesmo a distância, exerce controle sobre os passos e a atividade profissional de Sofia e, por extensão, sobre o exercício de sua sexualidade. Apesar da tentativa dele de proibi-la de se prostituir, o que ocorre é que, a partir dessa proibição Sofia desenvolveu algumas estratégias para violá-la, como a mudança do local de trabalho e do exercício da prostituição. Essa proibição e a vigilância coercitiva que lhe é decorrente estão intimamente relacionadas ao estigma da prostituição, construído sob as normas de gênero (Juliano, 2005), que cria dois universos dicotômicos - o mundo da "mulher honesta" e o da "prostituta". Ambos estão baseados em uma mesma premissa, que é a exigência que recai sobre as mulheres na forma de fidelidade e dedicação plena à família e ao marido. Desse modo, o ex-marido de Sofia a impediu, durante o tempo em que estiveram casados, de trabalhar como profissional do sexo - ainda que a tivesse conhecido por ter sido cliente dela - devido à suposta incompatibilidade dos papéis de esposa e prostituta. Essa separação sacramenta os lugares tradicionais e polarizados da mulher honesta e da puta. Vale ressaltar que o término do relacionamento não foi desencadeado pela prisão do marido, mas sim porque ele escolheu a ex-mulher, com quem tinha um filho, para ser beneficiária de sua pensão, o que Sofia interpretou como um rompimento da relação.

A entrevista foi realizada quando fazia duas semanas que Sofia havia retornado ao trabalho. Ela afirma estar enfrentando uma sensação de estranhamento por voltar a trabalhar como prostituta, depois de ter passado dois anos sem exercer a profissão devido à proibição do marido:

Não, nem quis [se prostituir enquanto estava casada]. Ficava só com ele. Nem tava consentindo mais essa vida pra mim, nem queria mais. Tava bem, bem demais. [...] A gente até hoje estava com a pessoa, depois vem voltar a trabalhar, ficar se esfregando no corpo de um monte de homem. Tem hora que eu fico até assim, que eu fico, sabe, virando a cara, porque, nossa, tem tempo que eu 
não entregava meu corpo pra ninguém. Era só pra ele. Só com ele. Desacostumei dessa vida. (Sofia)

Sabe-se que o trabalho sexual na rua é de alta vulnerabilidade, pois envolve maiores riscos do que o exercício da prostituição em ambiente fechado e protegido, em razão de estar exposta nas calçadas a todo tipo de violência, de clientes a transeuntes que "gostam de barbarizar as meninas", como Sofia diz. No entanto, essa busca por maior segurança pessoal não parece ser o fator preponderante que fez a participante abandonar as ruas. É interessante observar que o motivo determinante para Sofia buscar a casa para poder exercer o trabalho sexual foi se preservar da vigilância cerrada do marido, que, mesmo confinado em um presídio, a mantinha sob controle.

Por não saber ler e escrever, ela teve limitadas opções de escolha ocupacional. Frente à escassez de alternativas laborais que estão ao alcance de mulheres pobres e/ou com baixa qualificação profissional, a prostituição se mostra uma alternativa possível, interessante e rentável (Juliano, 2005). Nota-se que, apesar de Sofia ter escolhido prostituir-se - tanto da primeira vez que ingressou na atividade, há quatro anos, quanto de seu retorno mais recente - essa escolha não foi feita sem um certo grau de coerção de suas condições materiais de existência: analfabeta, mãe solteira, um filho que requeria cuidados especiais de saúde e recém-abandonada pelo homem que a sustentava financeiramente. Põe-se em cheque, assim, a noção de consentimento, baseado em ideais liberais, compreendido como "um ato de vontade, capacidade para exercer livremente a própria vontade [...] que tem como pré-requisito o autodomínio, isto é, um self livre de coações e constrangimentos" (Lowenkron, 2015, p. 230).

Estando Sofia em uma situação de tantas relações de desigualdade social e opressão, questiona-se: em que medida ela tomou a decisão de se prostituir livremente? Em que medida essa decisão não foi influenciada por suas condições materiais de existência, uma vez que a própria Sofia afirma estar tendo dificuldades em se prostituir (afirmando que por vezes se sente tão desconfortável que "vira a cara" para o cliente), e que, quando interrompeu essa atividade, estava bem e não sentia falta da prostituição? Para que se compreenda com mais profundidade a decisão de Sofia de se prostituir não se pode perder de vista que o consentimento não está descolado da categoria vulnerabilidade. Escolhas, muitas vezes, não são feitas de maneira livre nem autônoma, e a vulnerabilidade de Sofia parece ter sido motivadora de sua escolha de se prostituir.

\section{Negritude, feminilidade e sexualidade}

Se vidas reais são forjadas a partir da interação das categorias de articulação (Brah, 2006), a narrativa de Sofia é circunscrita por uma categoria que é forte marcador de diferença entre as relações sociais e que a diferenciava das demais mulheres de seu local de trabalho: era a única mulher negra na casa $\mathrm{e}$ a que tinha o mais baixo grau de escolaridade, o que foi evidenciado por meio das entrevistas realizadas com outras mulheres que ali trabalhavam. Observa-se, pelos relatos, que suas relações naquela casa eram permeadas pelo fato de ser negra, que naquele contexto é um significante de opressão. Além disso, há outras características que a diferem das demais mulheres da casa. Sofia é a única que não teve outra profissão anterior à de prostituta. Todas as demais já haviam exercido outras atividades, sendo a mais comum a de vendedora, antes de se iniciarem no mundo da prostituição. Sofia também era a única mulher analfabeta. E a única que escolheu aquela casa como local de trabalho para se manter protegida da vigilância do companheiro. A experiência, relativamente recente, de ter se "desacostumado da vida" tem que ser compreendida dentro desse contexto mais amplo, em que se acumulam insatisfações e desconfortos de diversas ordens. Em diferentes momentos da entrevista ela relatou ter sido preterida pelos clientes por ser negra:

Os clientes aqui não gostam de morena, só gostam de branca. Demora [para ela ser escolhida por um cliente]. Que eu falei pra Sílvia [dona da casa]: Sílvia, vou ter que arrumar outro lugar, que se eu ficar aqui eu passo fome com o meu filho. Que aí eu não ganho. Se eu faço uma massagem, dois, três dias eu fico sem ganhar dinheiro... Que aqui todo mundo trabalha. (Sofia)

Se você ficar ali sentada, você vai ver o tempo todo que eu só fico ali sentada. Só fico sentada desde a hora que chego. Aí não sei o que está acontecendo, né, se o problema é comigo, ou se é o povo que não, não, que não sei, não me enxerga. Parece que eu sou invisível ali naquela sala. (Sofia) 
Nesses excertos de fala, nota-se que Sofia se sente desfavorecida em relação às demais colegas de profissão. Revela seu desapontamento por ser invisibilizada pelos clientes que frequentam a casa, que a menosprezam na medida em que dão preferência a outras mulheres, que são brancas. Na visão de Sofia, essas mulheres são consideradas mais atraentes pelos clientes e isso se revela, de maneira dolorosa, pelo fato de ela passar seus dias de trabalho aguardando pelos clientes, sentada na sala da casa ao invés de fazer programas, relegada como uma opção de menor valor e atratividade. Sentindo-se desvalorizada no mercado competitivo do sexo comercial, Sofia considera que não é percebida devido à discriminação racial que recai sobre ela. Ratifica-se, assim, sua situação de marginalização, que está incluída no sistema social (afinal, foi aceita pela dona da casa para trabalhar ali), mas em uma posição periférica, sem poder, legitimidade ou prestígio (Juliano, 2004) junto aos clientes e às colegas de trabalho.

Em muitas situações narradas, a participante mostra que suporta um sofrimento que comumente acomete as pessoas negras no Brasil: Sofia é subordinada a uma condição de inferioridade, tem suas capacidades físicas desvalorizadas e sente-se deslocada no contexto social (Ferreira, \& Camargo, 2011). A discriminação não está presente apenas em atos e palavras dos clientes, que materializam o preconceito. Nos recortes de falas apresentados a seguir, nota-se a subjugação de Sofia diante dos insultos das outras mulheres que trabalham na casa. Isso é feito, especialmente, por meio da sistemática desvalorização de suas características físicas. Seu cabelo é eleito como alvo preferencial do escárnio alheio:

Quando eu entrei aqui, todo mundo começou a tirar piadinha de mim porque eu sou a única pretinha, até a Sílvia. Falaram do meu cabelo, que o meu cabelo é duro, aí falaram... Todo mundo tirou ondinha de mim, tudo mundo, não vou falar de nenhuma não, porque foi todas. (Sofia)

Só tem tudo branca, só tem eu aqui de preta. Eu falei assim, foram falar do meu cabelo pro cliente: "Ah, você vai ficar com aquela neguinha? O cabelinho dela é duro". Então a gente fica chateada, entendeu? (Sofia)

No Brasil, são assumidas as características do branco europeu como representativas da supe- rioridade étnica do padrão caucasiano, enquanto que o negro, com características físicas diferentes, é subjugado como um tipo étnico inferior (Ferreira, \& Camargo, 2011). Isso é visível no caso de Sofia, uma vez que as mulheres que trabalham no mesmo local recriminam abertamente seu cabelo, que por não ser liso como das demais colegas brancas, é considerado "duro", "ruim", uma característica fenotípica que supostamente expressaria seu caráter inferior. Ou seja, uma diferença é tomada como índice legitimador de uma desigualdade que se traduz, em termos relacionais, na atribuição de um lugar desfavorecido na hierarquia social.

O território da diferença é um espaço de poder, e o poder toma forma a partir de articulações locais (Costa, \& Ávila, 2005). Na situação em questão, o poder do grupo hegemônico se faz presente a partir da depreciação de características físicas de Sofia, contrastadas em relação ao cabelo das outras mulheres, liso e loiro em algumas delas. Interessante notar que é o cabelo o atributo eleito como veículo do insulto, justamente essa parte do corpo feminino que, no contexto sociocultural, é considerada um marco definidor da feminilidade. Assim, no ataque ao cabelo de Sofia está involucrada a agressão a três aspectos de sua subjetividade, concomitantemente: a raça, a feminilidade e sua força de trabalho, uma vez que parece haver uma tentativa de boicote à entrada da participante no prostíbulo, por meio de sua difamação junto aos clientes da casa.

Esse movimento explícito de preconceito racial, que põe em marcha o movimento difuso de discriminação racial, é fomentado pelas mulheres que estão sob a mesma condição de exposição a preconceitos e à exploração de seu trabalho pelo fato de estarem inseridas no mercado do sexo comercial. Fica clara aqui a articulação das categorias de diferenciação. Apesar de compartilharem o pertencimento à categoria mulher e à categoria profissional do sexo, dentro desses dois grupos operam relações de poder que criam diferentes realidades, explicitando a categoria raça como instrumento de modificação de atributos do ser mulher, em um processo de racialização da sexualidade (Piscitelli, 2008).

Essa questão pode ser ilustrada com o caso de Laura. A condição de trabalho de Laura, outra prostituta da casa, que era branca e tinha cabelos lisos e olhos claros, era muito diferente da realidade de Sofia. Laura era o tempo todo requisitada pelos clientes para fazer programa, 
chegando ao ponto de, em uma mesma manhã, enquanto eu estava na sala de espera da casa, vê-la entrar no quarto com mais de um cliente, fato que, durante o período de pesquisa, observou-se não ser comum. A realidade é bem diferente para Sofia, que raramente é escolhida pelos clientes, a ponto de se sentir como se não fosse vista por ninguém. Desse modo, tomando Laura e Sofia como exemplo de como operam as relações sociais na casa, percebe-se a construção de duas realidades distintas: por um lado, a feminilidade e a sexualidade de Laura são valorizadas como características desejadas; por outro, a sexualidade de Sofia é relegada ao desprezo e chacota. Trata-se de uma experiência de racismo gendrado, que se dá na intersecção entre gênero e raça, e produz experiências particulares às mulheres dos grupos raciais minoritários (Cardoso, 2012).

O racismo gendrado do qual Sofia é alvo preferencial redunda em violências de diversos matizes: psicológica, pelo sentimento de invisibilidade e inferioridade decorrentes da rejeição dos clientes; material, já que menos programas consumados implicam em menor ganho financeiro; e racial, uma vez que essa situação decorre do fato de ser negra e a maioria absoluta dos clientes e das mulheres da casa ser branca, o que dá margem a provocações e insultos diários.

\section{Estratégias de resistência: a deslegitimação do discurso discriminatório}

Como Sofia se posiciona em relação a essa tensão, permanente e tácita, vivenciada no relacionamento com as colegas de casa, e que acarreta a exposição frequente a situações discriminatórias? No excerto a seguir, Sofia narra uma situação em que ela confrontou as outras mulheres da casa e apontou, categoricamente, que elas se divertiam fazendo comentários maldosos e preconceituosos sobre sua pessoa:

Não, vocês todos são racistas. Porque é preto que, vocês falam que preto fede, vocês falam que vocês não querem fazer programa com preto porque preto fede, ô, eu sou preta. Você está falando da minha cor, eu não vou aceitar que falem mal da minha cor. Só tem tudo branca, só tem eu aqui de preta. (Sofia)

É perceptível nessa fala que, a despeito das mulheres da casa compartilharem o pertencimento a algumas categorias de articulação, como o gênero feminino e o trabalho sexual, é a categoria raça que se sobressai como um forte marcador de diferença, desencadeando vivências de menos-valia, isolamento e exclusão. Sem usar de meios tons ou subterfúgios, Sofia declara ser "a única negra" no seu local de trabalho, mostrando que ela se percebe diferente do restante das trabalhadoras da casa. Apesar disso, Sofia não assume uma posição submissa, não se deixa subjugar pelo roteiro - tão conhecido por ela - da humilhação social. Os estudos de Lélia Gonzalez apontam que as mulheres negras intervêm ativamente na condução dos seus destinos e deixam, como legado de sua resistência, a experiência do enfrentamento do racismo e do sexismo (Cardoso, 2012).

Para se defender, Sofia reitera que é negra e não permitirá que sua raça seja menosprezada e ofendida. Nesse contexto, a palavra "negra" perde seu significado negativo, seu teor fortemente pejorativo, pois passa a ser uma expressão emblemática de uma identidade afirmativa (Brah, 2006), que reforça a autoestima e a autoconfiança. Ela assume sua condição de negritude em um discurso afirmativo: "eu sou preta", "não vou aceitar que falem mal da minha cor". No relato, a afirmação de que é negra assume o significado de resistência contra o racismo e a opressão que ela vivencia nas relações estabelecidas no prostíbulo. O pertencimento ao grupo social definido pela cor da pele não é negativo em sua essência, e pode assumir significados culturais diferentes a depender do sentido conferido pela narrativa que o indivíduo é capaz de produzir para articular uma resposta frente à manifestação ofensiva recebida. No excerto de fala a seguir, Sofia retoma o tema do comentário ofensivo que teria sido feito por outra mulher, ao dizer que "preto fede":

Mas também não vou ficar aceitando todo mundo ficar toda hora falando mal de preto perto de mim, que eu não vou aceitar porque eu sou negra, não aceito. Se tiver uma pessoa que é branca e estiver numa roda de negro, vai aceitar que fale mal de branco? Não vai. Falei: "Não é só preto que fede, branco fede, preto fede, se não tomar banho". Agora, esse tempo todo ficar falando que preto fede? Agora pararam com essas piadinhas, mas quando eu entrei aqui fiquei muito tempo... fiquei uma semana aguentando essas piadinhas. (Sofia)

Essa fala desvela alguns mecanismos subjacentes ao preconceito. A atitude preconceituosa que se 
expressa nos atos de discriminação pela cor pode ser ostensiva ou tácita. "Falar mal de preto" na presença de Sofia equivale a conferir-lhe uma posição de invisibilidade social, pois é como se fosse possível abstrair sua condição de negra ao posicioná-la como ouvinte de um comentário abertamente racista. Ademais, o ataque grosseiro torna-se ainda mais eficaz em seu propósito depreciativo à medida que a ofensa é desferida de forma indireta, dando margem ao ofensor de se defender de uma eventual retaliação, alegando, por exemplo: "não quis dizer isso de você" ou "fique tranquila, é claro que isso não se aplica a você".

O processo de construção identitária passa pela criação de um sujeito "nós", que compartilha características que são pressupostas como sendo comuns a todos os indivíduos em contraposição aos "outros" (Juliano, 2004). No excerto de fala nota-se que há uma tentativa das mulheres brancas de fortalecer um grupo identitário formado exclusivamente por pessoas brancas, embora fincadas em uma condição de subalternidade social, em oposição ao grupo de pessoas negras. Para as mulheres brancas da casa, uma característica que diferencia o grupo dos brancos e dos negros é que "preto fede", e a estigmatização e rotulação engendram o distanciamento contrastando os dois grupos.

Segundo Ferreira e Camargo (2011), o preconceito é legitimado quando o grupo dominado compartilha das crenças de inferioridade sobre si mesmo e se submete à dominação. Os autores afirmam que uma das estratégias adotadas por pessoas negras que enfrentam situações de discriminação é o silêncio, o que é problemático, pois o indivíduo passa sua vida em uma situação de submissão e não enfrentamento. Essa postura de subserviência, por sua vez, acaba por alimentar a opressão. Não parece ser o caso de Sofia. Ela não compartilha as crenças das outras mulheres ou dos clientes sobre sua pessoa, questiona as afirmações generalistas das mulheres sobre os clientes negros, e aponta as atitudes racistas das mulheres. Desse modo, a intervenção de Sofia promove uma quebra no discurso racista institucionalizado da casa, atitude política que interrompe e problematiza o fluxo das relações, já naturalizado e pouco questionado no cotidiano.

Diante da percepção de que suas experiências são moldadas pelo pertencimento à categoria da diferença, Sofia assume uma postura de enfrentamento, tentando desconstruir o distanciamento que está sendo criado entre o grupo de brancos e de negros por meio de generalizações depreciativas. Como afirma Brah (2006), a experiência é um lugar de contestação: Sofia contesta a realidade que é dada como natural, a suposta verdade que estaria sendo revelada no enunciado vil e preconceituoso de que "preto fede". E contesta de forma veemente que a diferença seja predeterminada, apontando semelhanças entre o grupo social que, na visão das mulheres da casa, é considerado diferenciado. Desse modo, Sofia desconstrói a generalização pejorativa (todos os pretos fedem), que é a base da criação dos estereótipos e, no limite, da discriminação racista.

Sofia, por outro lado, afirma que não se sente pertencente ao grupo das prostitutas que trabalham na casa, chega a cogitar com a dona do negócio a possibilidade de se afastar. Seu sentimento de não pertença fica claro quando faz da pesquisadora confidente de um segredo que até então não havia compartilhado com nenhuma das mulheres da casa:

Que também, os homens que me chamam, [fala baixo] falam que as mulheres aqui fazem muito programa sem camisinha. E os clientes fala que elas fazem. Elas faz tudo sem camisinha. Aí eu falo pra Sílvia: "Sílvia, então muita mulher não ganha dinheiro”, e os homens espera até elas sair do quarto pra fazer programa com elas. (Sofia)

Sofia me confidencia que algumas mulheres da casa aceitam fazer programas sem usar preservativo. Até aquele momento, nenhuma mulher havia me dito isso. Pelo contrário, todas haviam assegurado que o preservativo era uma condição essencial para a realização do programa. O fato de Sofia "denunciar" uma espécie de tema-tabu da casa pode ser um indicativo de que ela não se sente obrigada a ser cúmplice daquele segredo, talvez porque não se sinta pertencente ao grupo de mulheres da casa. Chega, inclusive, a responsabilizá-las pelo baixo número de programas que realiza, pois afirma que os clientes preferem as mulheres que fazem programa sem preservativo, e ela, que só aceita sob a condição de sexo protegido, seria preterida pelos homens. No excerto a seguir, Sofia me confidencia outro "segredo" da casa:

Sofia:Veio um moço aqui, ontem e anteontem gastou cinco mil. Foram quatro meninas, roubaram o homem. O homem voltou aqui ontem. Uma tirou mil e pouco, outra tirou 800. O homem estava bêbado, elas acharam que o homem não ia perceber. 
Pesquisadora: E ele percebeu?

Sofia: Lógico, né, gata. Claro, ontem ele voltou aqui. $\mathrm{E}$ as meninas falaram que não roubou, quem vai falar que roubou do homem?

A confissão, dessa feita, de um ato delituoso que teria sido praticado pelas mulheres da casa, mostra que Sofia não se sente confortável com a situação e compartilha com a pesquisadora um segredo que diz respeito às pessoas que pertencem àquele lugar. Expor a contravenção praticada pelas colegas de trabalho pode ser uma forma de retaliação contra sua exclusão do grupo de mulheres, como se o preço a ser pago por excluírem e segregarem Sofia fosse ter seus segredos e comportamentos delinquentes expostos a terceiros.

Outra forma de protesto e resistência se expressa na manifestação de que ela pretende deixar de trabalhar na casa, onde tem poucos ganhos financeiros, fato que ela atribui à discriminação racial dos clientes, insuflada pelos comentários depreciativos das outras mulheres do prostíbulo. Atualmente, Sofia vem considerando a possibilidade de voltar a trabalhar "na rua", onde acredita que conseguiria fazer programas com mais facilidade, sem se sujeitar à concorrência desleal das colegas e sem ter que dispor parte dos seus ganhos para a pessoa que administra a casa.

É barato, 60 reais, mas é 60 reais um atrás do outro, é 30 minutos cada. Aqui é uma hora no quarto, duas gozadas, cê é loca? Me acabo aqui, acaba com a gente. Homem quer ficar metendo, depois tem que meter com o homem de novo? Não. Eu vou pra lá, 60 reais, mas um atrás do outro. É 60 reais, mas é um... Eu tirava mil reais por dia. [enfática] Mil! Chegava sete e meia da manhã, ficava até nove da noite. Mil reais assim, ó! Eu falava, eu comentei isso aqui dentro... Mas elas são preconceituosas: "Ai, só 60 reais?". Mas enquanto você faz um de 100 , de 80 aqui, você já fez uns quatro lá. É assim, o preço é diferente? É. Mas eu prefiro com um preço mais barato do que com um preço que é 100,80 , e que você faz um e depois não faz mais nenhum. (Sofia)

Esse excerto mostra que, apesar de afirmar sentir certo estranhamento por ter voltado a fazer programas, Sofia preza pela autonomia que encontra no trabalho que exerce e se sente perfeitamente capaz de fazer escolhas profissionais de acordo com o que lhe é mais conveniente e rentável. A rua, apesar de ser um local de grande exposição, em que ela está sujeita a ser descoberta pelo ex-marido, é para Sofia um lugar onde ela sente que tem maior liberdade para estabelecer o preço de seu programa e maximizar a relação custo-benefício no exercício de seu trabalho, além de ser livre para organizar seus horários e escolher quantos e quais clientes vai atender. Ela afirma que na rua faz mais programas porque o preço é menor, em comparação à casa. Além disso, a prostituição de rua implica elevado grau de mobilidade e rotatividade (Mayorga, 2011), o que parece ser um atrativo para Sofia, que deseja exercer a profissão sem o conhecimento do ex-marido.

Outra vantagem considerada por Sofia é o tempo do programa. Na casa, o tempo do programa é previamente determinado, sendo uma regra daquele local fixar o tempo do programa em uma hora. Na rua, o programa é significativamente mais rápido, cerca da metade do tempo que leva o programa na casa, de acordo com o relato. Sofia prefere um tempo menor a um programa mais longo, em que o esforço despendido pela profissional para satisfazer sexualmente o cliente é proporcionalmente maior, gerando maior desgaste. Segundo ela, a maior rotatividade de clientes acaba se tornando menos cansativa do que despender mais tempo com um único cliente.

O desejo de voltar a fazer programas narua, ao invés de permanecer no esquema supostamente protegido da casa, tem uma dupla implicação. A primeira é que mudar o local de trabalho é uma forma de deixar um ambiente no qual ela sofre com a discriminação racial. Portanto, é um modo de minimizar os efeitos do racismo do qual é vítima e preservar sua dignidade. No entanto, Sofia retornaria para um ambiente de trabalho onde o programa é mais barato, e ela teria que trabalhar mais (angariar mais clientes) para ganhar a quantia que uma profissional que atua em uma casa de prostituição ganharia. Vê-se, assim, que Sofia sente dificuldades em ingressar em um ambiente de trabalho que, por um lado, mostrou ser altamente competitivo e racista e, por outro, oferece a promessa de melhor remuneração e ambiente protegido.

Esse espaço parece estar reservado às mulheres brancas. Nele Sofia se sente excluída. Isso porque existe uma relação de poder e as mulheres brancas daquele contexto particular para preservarem certos privilégios, apoiam-se na tradição escrava- 
gista de nosso país, onde as mulheres negras têm sido historicamente designadas como "outras". Desse modo, Sofia é designada como uma "outra", mesmo estando inserida na categoria de prostituta. Assim, é a "outra" dentre as "outras". Está, de certo modo, à margem da margem. Por isso, um grau de tensão crescente domina o clima da casa, com manifestações abertas de injúria e difamação em decorrência dos ataques racistas.

O desfecho desse estado de coisas pôde ser observado algum tempo depois. Em um trabalho de campo realizado algumas semanas após concluída a entrevista, encontrei Sofia na rua, à espera de clientes para fazer programa.

\section{Considerações finais}

O sujeito, constituído em gênero, classe e etnia, não é homogêneo. A depender de suas condições histórico-sociais, uma dessas facetas será mais proeminente, enquanto as outras, mesmo vívidas, colocam-se à sombra das primeiras (Saffioti, 1999). Em um ambiente em que as mulheres compartilham o pertencimento à categoria de gênero, e que a categoria classe social é relativamente ocultada, a categoria que parece ser a mais proeminente, e que inclusive baliza a relação de Sofia com o seu contexto de trabalho, é a raça.

O presente estudo confere visibilidade ao fato de que, na interseccionalidade gênero e raça, preconceito e discriminação se conjugam como expressões de violência perpretada contra a mulher negra profissional do sexo. Em um ambiente de prostituição, os preconceitos de raça ganham contornos específicos. Vimos também que, por meio da interseccionalidade entre essas categorias, Sofia e as demais negociam suas fronteiras identitárias, sendo essa fronteira delimitada, principalmente, pelo pertencimento a uma categoria racial ou outra. As outras mulheres da casa, brancas, estabelecem com Sofia uma relação de poder racializada, baseada na diferença racial, assumida como índice de superioridade e desigualdade. Essa estratégia é materializada por um discurso racista, dirigido aos clientes da casa, que inferiorizam suas características físicas, como a cor da pele e o cabelo. A disseminação desse discurso constrói um lugar de desqualificação pessoal e laboral para Sofia, que resiste tenazmente a ocupá-lo, embora exista pouca margem de manobra para não se deixar capturar pela malha opressiva, que se robustece pela reiteração e competição profissional.

Sofia suporta o sofrimento produzido por inúmeros percalços. Está sujeita a atos recorrentes de preconceito e discriminação racial, tendo sido referidas neste estudo diversas situações que evidenciam os desafios enfrentados em seu cotidiano. As manifestações veladas ou abertas de preconceito e discriminação emanam dos clientes da casa, que quase não a selecionam para fazer programas, e são potencializadas pelas outras mulheres que trabalham no prostíbulo.

Isso evidentemente não anula a vivência de opressão devido a seu pertencimento a outras categorias. Os resultados apresentados refletem os efeitos interativos entre as discriminações de raça e de gênero, sugeridos por estudos anteriores (Crenshaw, 2002). Em sua condição de mulher, negra e pobre, Sofia enfrenta diversas formas de opressão que não são da mesma natureza. É oprimida pela desigualdade de gênero, uma vez que recai sobre ela, que é mulher, a responsabilidade de cuidar do filho que é fruto de uma gravidez não planejada. É excluída no exercício de seu trabalho pela cor da pele e também tem a atividade profissional regulada pelo companheiro, que, ainda que ausente fisicamente, exerce seu controle a distância, manipulando "olheiros" para constrangê-la a "manter-se na linha".

O desafio para a pesquisadora desse cenário é conseguir apreender tanto os aspectos de gênero da discriminação racial quanto os aspectos raciais da discriminação de gênero. Além disso, outra categoria - classe social - contribui para a inteligibilidade do fenômeno investigado. Pertencer a um estrato social desfavorecido contribuiu para que Sofia tenha estudado somente até a quarta série do Ensino Fundamental e, mesmo assim, não tenha sido alfabetizada. $\mathrm{Na}$ transição para a maternidade, as dificuldades financeiras motivaram que ela iniciasse sua vida no mercado do sexo comercial. Os eixos investigados confluem, na história de vida de Sofia, no sentido de construir sua identidade e seus papéis sociais.

Todavia, a despeito da extrema vulnerabilidade social, Sofia não assume uma posição de resignada submissão. Pelo contrário, mantém uma posição de enfrentamento ativo frente às atitudes discriminatórias com as quais se depara em seu cotidiano. Estar em uma posição de subalternidade viabiliza a criação de estratégias de resistência (McKlintock, 1995), e Sofia, dentro do que permite sua condição social, se opõe ao 
discurso de opressão. Ela relata o desejo de trabalhar em um lugar onde não seja constrangida ou impedida de fazer programa devido à discriminação racial e aponta diretamente para as mulheres quando elas estão insuflando os clientes com comentários racistas, afirmando sua identidade de mulher negra no embate cotidiano. Desse modo, ela não se mostra resignada com o lugar de inferioridade que lhe é reservado pelas pessoas de seu contexto de trabalho. Na luta por manter sua dignidade e assegurar sua subsistência, Sofia afasta-se do trabalho do prostíbulo e recupera sua autonomia profissional ao voltar para as ruas.

Como apontamentos de futuros estudos, que apontem novos horizontes de pesquisa, espera-se que este estudo de caso motive a realização de outros,

\section{Referências}

Barreto, L. C. (2013). Prostituição, gênero e trabalho. Rio de Janeiro, RJ: Multifoco.

Brah, A. (2006). Diferença, diversidade, diferenciação. Cadernos Pagu, (26), 329-376. doi:10.1590/S0104-83332006000100014

Brasil (1940). Câmara dos Deputados. Decreto-lei no 2.848, de 7 de dezembro de 1940. Código penal. Recuperado de http://www2.camara.leg.br/legin/ fed/declei / 1940-1949/decreto-lei-2848-7-dezembro-1940-412868-normaatualizada-pe.html

Brasil (2008). Ministério do Trabalho e do Emprego. Classificação Brasileira de Ocupações: Prostituta. Recuperado de http://www.mtecbo.gov.br/cbosite/ pages/pesquisas/BuscaPorTituloResultado.jsf

Braun, V., \& Clarke, V. (2006). Using thematic analysis in psychology: qualitative research. Psychology, 3(2), 77-101. doi:10.1191/1478088706qp063oa

Cardoso, C. P. (2012). Outras falas: feminismos na perspectiva de mulheres negras brasileiras (Tese de doutorado). Universidade Federal da Bahia, Salvador.

Costa, C. L., \& Ávila, E. (2005). Gloria Anzaldúa, a consciência mestiça e o "feminismo da diferença”. Revista Estudos Feministas, 13(3), 691-703. doi:10.1590/S0104-026X2005000300014

Crenshaw, K. (2002). Documentoparao encontrodeespecialistas em aspectos da discriminação racial relativos que desvelem as facetas do racismo sofrido especificamente por mulheres e as estratégias de enfrentamento que elas adotam para resistir a essa situação. A potencial contribuição dessa investigação para a área de conhecimento é possibilitar "articular discursos e práticas, que inscrevem relações sociais, posições de sujeito e subjetividades" (Brah, 2006, p. 359).

Isto posto, é importante pontuar as limitações do presente estudo. Em decorrência de Sofia ter iniciado o trabalho na casa duas semanas antes da entrevista, e depois do início da observação participante, o tempo da interação entre Sofia e a pesquisadora foi curto, inviabilizando uma observação mais aprofundada das relações travadas entre ela, as outras prostitutas e os clientes da casa.

ao gênero. Revista Estudos Feministas, 10(1), 171-189. doi:10.1590/S0104-026X2002000100011

Delmanto, C. (1991). Código Penal comentado e ampliado. São Paulo, SP: Renascer.

Ferreira, R. F., \& Camargo, A. C. (2011). As relações cotidianas e a construção da identidade negra. Psicologia: Ciência e Profissão, 31(2), 374-389. doi:10.1590/S1414-98932011000200013

Gaspar, M. D. (1985). Garotas de programa: prostituição em Copacabana e identidade social. Rio de Janeiro, RJ: Jorge Zahar.

Juliano, D. C. (2005). El trabajo sexual en la mira: polémicasyesteriotipos. CadernosPagu, (25),79-106. doi:10.1590/S0104-83332005000200004

Juliano, D. C. (2004). Marginalización y exclusíon en la construcción de género. In: D. C. Juliano (Org.), Excluidas y marginales: una aproximación antropológica (pp. 1-16). Madrid: Cátedra.

Kerner, I. (2012) Tudo é interseccional? Sobre a relação entre racismo e sexismo. Novos estudos - CEBRAP, (93), 45-58. doi:10.1590/S0101-33002012000200005

Lowenkron, L. (2015). Consentimento e vulnerabilidade: alguns cruzamentos entre o abuso sexual infantil e o tráfico de pessoas para fim de exploração sexual. Cadernos Pagu, (45), 225-258. doi:10.1590/18094449201500450225 McKlintock, A. (1995). Imperial leather: race, gender and sexuality in the colonial context. New York, NY: Routledge. 
Mayorga, C. (2011). Cruzando fronteiras: prostituição e imigração. Cadernos Pagu, (37), 323-355. doi:10.1590/S0104-83332011000200014

Mayorga, C., Coura, A., Miralles, N., \& Cunha, V. M. (2013). As críticas ao gênero e a pluralização do feminismo: colonialismo, racismo e política heterossexual. Revista Estudos Feministas, 21(2), 463-484. doi:10.1590/S0104-026X2013000200003

Moscheta, M.S., McNamee, S., \&Santos, M.A. (2013).Sex trade among men: negotiating sex, bodies and identity categories. Psicologia \& Sociedade, 25(n.spe), 44-53. doi:10.1590/S0102-71822013000500006

Olivar,J.M.N.(2011).Banquetedehomens:sexualidade, parentesco e predação na prática da prostituição feminina. Revista Brasileira de Ciências Sociais, 26(75), 89-101. doi:10.1590/S0102-69092011000100005

Peres, R. S., \& Santos, M. A. (2005) Considerações gerais e orientações práticas acerca do emprego de estudos de caso na pesquisa científica em psicologia. Interações, 10(20), 109-126. Recuperado de http:// pepsic.bvsalud.org/scielo.php?script=sci_arttext\&pid=S1413-29072005000200008

Piscitelli, A. (2005). Apresentação: gênero no mercado do sexo. Cadernos Pagu, (25), 7-23. doi:10.1590/S0104-83332005000200001

Piscitelli, A. (2008). Interseccionalidades, categorias de articulação e experiências de migrantes brasileiras. Sociedade e Cultura, 11(2), 263-274.

Rubin, G. S. (1984/1993). Thinking sex: notes for a radical theory of the politics of sexuality. In H. Abelove, M. Barale, \& D. Halperin (Eds.), The lesbian and gay studies reader (pp. 3-44). New York, NY: Routledge. (Trabalho originalmente publicado em 1984).

Saffioti, H. I. B. (1999) Já se mete a colher em briga de marido e mulher. São Paulo em Perspectiva, 13(4),82-91. doi:10.1590/S0102-88391999000400009

Santos, M. A. (2010). Tem gato na tuba: a inserção de jovens homens no mercado de trabalho sexu- al. In M. A. T. Bruns \& C. R. V. Souza-Leite (Orgs.), Gênero em questão: diversos lugares, diferentes olhares (pp. 145-162). São Paulo, SP: Iglu.

Santos, M. A. (2011). Prostituição masculina e vulnerabilidade às dsts/aids. Texto \& Contexto Enfermagem, 20(1), 76-84. doi:10.1590/S0104-07072011000100009

Stake, R. E. (2000). Case studies. In: N. K. Denzin, \& Y. S. Lincoln (Eds.). Handbook of qualitative research (pp. 435-454). London: Sage.

VandeBos, G. R. (Org.). (2010). Dicionário de psicologia da APA. (D. Bueno, M. A. V. Veronese, \& M. C. Monteiro, Trads.). Porto Alegre, RS: Artmed.

\section{Raquel de Freitas Banuth}

Acadêmica de Psicologia da Universidade de São Paulo, São Paulo - SP. Brasil.

E-mail: raquel.fbanuth@gmail.com

\section{Manoel Antônio dos Santos}

Doutor. Docente da Universidade de São Paulo, São Paulo - SP. Brasil.

E-mail: cgcapitao@uol.com.br

Endereço para envio de correspondência:

Universidade de São Paulo, Faculdade de Filosofia, Ciências e Letras de Ribeirão Preto, Departamento de Psicologia. Avenida Bandeirantes, 3900, Monte Alegre. CEP: 14040901. Ribeirão Preto-SP. Brasil.

Recebido 04/09/2015

Aprovado 12/08/2016

Received 09/04/2015

Approved 08/12/2016

Recibido 04/09/2015

Aceptado 12/08/2016

Como citar: Banuth, R.F., \& Santos, M. A. (2016). Vivências de discriminação e resistência de uma prostituta negra. Psicologia: Ciência e Profissão, 36(3): 763-776. doi:10.1590/1982-3703002862015

How to cite: Banuth, R.F., \& Santos, M. A. (2016). Experiences of discrimination and resistance of a black prostitute. Psicologia: Ciência e Profissão, 36(3): 763-776. doi:10.1590/1982-3703002862015

Cómo citar: Banuth, R.F., \& Santos, M. A. (2016). Experiencias de discriminación y resistencia de una prostituta negra. Psicologia: Ciência e Profissão, 36(3): 763-776. doi:10.1590/1982-3703002862015 